\title{
Terrorism as a Form of Design Critique
}

\author{
Thomas Fisher \\ Professor of Architecture and Dean of the College of Design, University of Minnesota.
}

doi:10.5618/arch.v2.2 || Received: 2013-01-14, Accepted: 2013-01-15, Available online: 2013-01-15

\begin{abstract}
Terrorists exploit design flaws in or unidentified conflicts among our infrastructures in order to maximize their impact with a minimum of means. As such, they serve as astute - and terrifying critics of our designed systems. At the same time, we can defend ourselves against them not by responding to their attacks after the fact, as often happens now, but by anticipating their next moves through the same design thinking that they use against us, and by improving the conditions of people so that they are not tempted to become terrorists in the first place.
\end{abstract}

Keywords: Terrorism, Design, Criticism, Open Society, Freedom

\section{Introduction}

Terrorist acts have happened with increasing frequency around the world. In 2010 alone, we saw 103 reported terrorist attacks - mainly bombings and assassinations - occurring in over 30 countries, killing at least 1,368 people and injuring at least 4,324. [1] While the world community has rightfully condemned such violence, these politically motivated assaults by non-governmental assailants against un-armed civilians have also highlighted our own vulnerabilities. Terrorism relies not only on the element of surprise, but also on the ingenuity of its perpetrators in exploiting weaknesses in vital infrastructure and in imagining how different systems rarely thought of as interrelated can catastrophically fail when brought together. With perversely elegant efficiency, terrorists have learned how to spread the maximum fear and leverage the maximum response from victims with the minimum effort and expense apart, of course, from the fact that terrorists often willingly lose their lives in the act.

Countries around the globe, but especially the United States, have responded by doing precisely what the terrorists have no doubt intended. More often than not we have over-reacted (it's useful to remember that we are more likely to be struck by lightning than attacked by a terrorist), and invested huge sums to defend against such threats. The General Accounting Office, in 2004, reported that the U.S. alone spent \$11 billion on non-military efforts to combat terrorism overseas, and by 2006, the budget for the Department of Homeland Security for security inside the U.S. amounted to $\$ 30.8$ billion. [2] When we compare what just 19 people spent to carry out their devastating attacks on 9/11 against the Pentagon and the World Trade Center — tuition for flight training school, household tools available at any hardware store, a few domestic airfares - versus what the U.S. has spent since then to combat terrorism, we can see how extraordinarily effective a very small group of modestly funded terrorists can be in commanding the attention and sapping the resources of a superpower

We have come to the point where nations fighting terrorists find it difficult to know whether or not they have succeeded - or even what actually constitutes a victory. As a 2007 Congressional Research Service report, Combating Terrorism: The Challenge of Measuring Success, put it: "Among the various U.S. government agencies involved in anti-terrorism efforts, there is currently no common set of criteria for measuring success." The report goes on to liken terrorist activity to "a process, which includes discrete, quantum-like changes or jumps often underscoring its asymmetric and nonlinear nature." [3]

\section{Rethinking Anti-Terrorism}

If terrorism does, indeed, have a quantum-like character, then conventional defenses are likely to be ineffectual in fighting it - perhaps because we have been thinking in terms of the wrong metaphor. Terrorists may be our enemies, intent on doing us harm, but their ability to leap to new tactics in unpredictable ways - as we saw in $9 / 11$ when they moved from the detonating of car bombs to the hijacking of fully loaded jets - requires that we think in new ways. As the old military saying goes: we cannot win the next war by fighting the last one. The intrusive and costly efforts we devote to screening people and baggage at airports, for example, assume that what terrorists have tried once, they will try again. While some level of screening makes sense terrorism or not - it does little good when terrorists already seem to have moved on to new tactics, such as shipping explosives overseas in printer cartridges. Passenger screening at airports might even lull us into thinking that we are safer than we are, and distract us from the vital work of anticipating the new format and different locations of future attacks. 
Rather than focus so much on protecting ourselves against the last type of attack, we should work instead to develop more creative strategies, such as the FBI's providing the suspected terrorist in Portland, Oregon, a dummy bomb and waiting to see how he planned to use it before arresting him. Better yet, we should try to think like terrorists, to imagine where and how they might attack before they do, acknowledging the creative thinking that they deploy in devising attacks and preempting them. Why should we have been surprised that terrorists, stymied by passenger screening at airports, would instead send explosives in minimally screened packages in shipping containers?

Terrorism, in other words, serves as a kind of critique of the design flaws in our systems. These assailants have taken advantage of weaknesses we have often overlooked and exploited gaps we have not considered carefully enough, and the more we can recognize those shortcomings and close those gaps before terrorists get there, the more we will succeed in stopping them, at a much lower cost. If, for example, car bombs remain difficult to detect, then why do we even allow cars in crowded pedestrian districts, as happened with the aborted car bombing in Times Square? Might we find that good urban design thinking can also prove effective in thwarting terrorists?

Acknowledging the creative critique embedded in terrorist acts does not mean that we should condone or even admire the acts or their politics. And thinking of terrorism as a form of design critique - albeit unintentional - may seem far removed from our current approach to anti-terrorism, which has focused on reactive tactics rather than on the creative speculation and scenario building that characterizes design thinking. But these are not mutually exclusive. We clearly need to keep our guard up, but we can achieve a much greater level of protection at much lower cost by beating the terrorists at their own game, and using the same degree of low-cost innovation against them that they have used against us.

\section{Places Terrorists Strike}

Out-imagining terrorists might begin by looking, generically, at where they have struck and with what strategies in mind. For example, did the 9/11 terrorists at some point identify the gaps between seemingly disconnected systems, and then exploit those gaps by bringing the systems together, stressing them beyond their designed limits, and causing their catastrophic failure? Think about it: We designed highly efficient skyscrapers such as the twin towers, and we developed an extensive and efficient airline system, with planes able to fly very fast, fully loaded with people and fuel. But in neither case did we design these two systems to withstand a direct, full-speed collision, even though their proximity in large cities has always made this a distinct possibility. The 9/11 terrorists saw this flaw in the design and operation of the airline and skyscraper systems and they took advantage of it, to spectacular and diabolical effect.

Terrorists also target places where large concentrations of people can congregate in relatively enclosed areas with few means of escape. In this way they use the density and proximity of an environment to their advantage and against us, maximizing death and destruction. We saw this strategy at work not only at the World Trade Center but also with the attack on the Pentagon. However well we had defended the U.S. Department of Defense from a ground attack, the terrorists saw its vulnerability from the air, given the proximity of two major airports and the frequency of commercial airline schedules. The presence of so many military people in the immense headquarters at 6.5 million square feet, the world's largest office building - made the Pentagon visible and vulnerable, almost impossible to defend fully.

And of course terrorists also identify popular public gathering areas, places with easy access, diverse populations, and events or activities that distract attention. We have seen this tactic in operation in the car bombings that have plagued major cities like Baghdad and in the similar actions that almost occurred in New York's Times Square or Portland's Pioneer Square. Here the vulnerability arises not from a gap between systems or the density of people within a system, but instead from the sheer number of people and systems intersecting in a given place. Karl Popper's The Open Society and its Enemies comes to mind here. [4] Terrorists - who hold what Popper called "the tribal ideal" - use the sheer openness of modern society against us. They seek, says Popper "an attack on the idea of civil life itself; this is denounced as shallow and materialistic, because of the idea of security which it cherishes."

\section{Preserving the Open Society}

We have seen how easily we can over-react to the threat of terrorism and relinquish our freedom. There exists a fine line between appropriate caution and palpable paranoia, and aspects of our physical environment have come to reflect our fears, with bollards around buildings that hardly seem like terrorist targets or surveillance cameras in places that appear unlikely to harbor bomb carriers. Even more disturbing has been the rise of racial or ethnic profiling in public places, with terrorism sometimes seeming like an excuse for some people to act out their prejudices, be they religiously, ethnically, or politically motivated.

So how can we resist terrorism while also maintaining an open society that values political freedom and human rights? To answer that question, we first need to challenge some of our assumptions 
about anti-terrorism. To prevent the collision of two systems, like airplanes and skyscrapers, for example, we should ask: Why continue to create such obvious targets - that is, a very tall building in an exposed location like the water's edge? And why we are rebuilding a very tall building - even taller than the twin towers - right at Ground Zero? While that action might have some cathartic value - as evidence of undefeated national spirit, civic pride, etc. — and clearly has real financial value to the owners and developers, it also shows - as some have observed - that we have not learned from the attack and have simply created a new — albeit more fortified target. A city of more uniformly high buildings, where the urban form is mat-like and where few structures stick up above the rest, makes the kind of aerial attack that happened in September 2001 much more difficult.

That may seem at odds with the way cities like New York have evolved, but other modern cities Washington and Paris, for example — have a much more uniform skyline, with central-city height limits in place for a long time, so these kind of restrictions do not necessarily undercut the economic viability or livability of cities. Indeed, height limits can increase urban viability and livability by increasing density more uniformly. Just because we can build high doesn't mean we should, and the terrorists have given us a compelling reason why.

One area in which the West seems to lack imagination lies in a widespread inability to understand what skyscrapers mean to many people around the world. At a time when, as Branko Milanovic of the World Bank put it, "the total income of the richest 25 million Americans is equal to the total income of almost 2 billion people," [5] tall towers, especially in financial capitals like New York, can become symbols of the profound inequities of the global economy and a target of people's rage. Moderating the lust for building ever-taller towers becomes not just a matter of defense, but of deference to the billions of people for whom such structures remind them of what they will never have a chance to achieve.

This may also help explain the frequent terrorist attacks on trains and airplanes and the buildings associated with them. Not just offering a concentration of people that terrorists like to target, such settings also symbolize the mobility of the world's wealthiest populations and the lack of it among the majority of people on the planet. Because of that symbolism, diversifying the types of transportation and moderating the concentrations of people in any one of them represents not just selfprotection, but also the self-effacement that comes from imagining how mobility must look like to those who have very little. Multi-modal strategies, including mass transit, electric vehicles, and bicycles, thus not only increase transportation options and decrease the over-dependence on fossil fuel, but also downplay the differences and possibly even enhance empathy for the diverse ways in which people move around the world.

Understanding the symbolism of wealth and poverty should lead us, as well, to question the large concentrations of people working in politically charged places like the Pentagon. While necessary in the past, when co-workers had to interact face to face, to transfer documents by hand, and so forth, such high populations in massive buildings have become not only less necessary in the digital age, but also less wise. We know from the research on telecommuting that distributing work among digitally linked and physically dispersed networks of employees can offer people greater flexibility in how and where they work, while enhancing their productivity and loyalty. Distributing employees, though, has the added benefit of reducing the likelihood any one building will become a target for terrorism since no place has many people doing a particular type of work. In a sense this uses terrorists' own strategy against them. Often operating in small, distributed cells, terrorist organizations have shown the resiliency of that model when under attack, and they are almost impossible to disrupt even with the capture of key individuals.

\section{Our Confusion over Freedom}

Such strategies may seem counter to what we have come to associate with our open society. Tall skyscrapers, high-speed transportation, and large-scale office complexes: all have become symbols of modernity, with its emphasis on maximizing individual freedom. The "Freedom Tower" at Ground Zero reflects this often-unquestioned assumption, as if choosing to construct a tower taller than the fallen ones expresses something important about the United States. But what freedoms might we be losing in the process? Do such symbols of freedom trump the loss of actual freedoms such as the ability to live without anxiety, ever-present surveillance or invasions of personal privacy? Does it make sense to keep constructing obvious and easily identifiable targets for terrorists when we can design other ways of living, working and traveling that would make it more difficult to attack?

As long as we see anti-terrorism in primarily defensive terms, we will not change the paradigm we have followed since $9 / 11$. Keeping existing targets in place - like the Pentagon - or building new ones as if to taunt the terrorists - like the Freedom Tower represents not a creative solution to the problem, but a confused one. If we don't want another terrorist attack, having buildings that seem to dare terrorists to attack again seems foolhardy, a matter of our ignoring 
the real design problem - and opportunity - that terrorism presents.

\section{What Designers Can Do}

Once we see global terrorism as an identification of the design flaws in our systems and infrastructures, we can start down a more sustainable and affordable path toward protecting ourselves. Design thinking can help in various ways.

First, designers can help us ask not how to keep doing what we have been doing, only with more security measures in hopes that we can catch the next attack before it comes, but rather how we can rethink what we have been doing to make such measures almost unnecessary. Good design achieves the greatest impact with the least expenditure, something that the terrorists have themselves done quite effectively. We can foil them if we become as creative as they have been, preventing them from disrupting our lives with the least expenditure on our part, not the most, as we are doing now. Ironically, the distributed networks of people, diverse modes of transportation, and modestly scaled buildings and neighborhoods that characterize cities in countries like Egypt and Pakistan from which many terrorists have come also offer models of how we can resist terrorist attacks, while also possibly living more connected and less compulsive lives than what many people endure in fast-paced, high-stress Western cities.

Second, designers can help us look not at what the terrorists have already done, but rather at where our enemies might attack in the future. That predictive aspect of design comes from understanding the nature of terrorists' strategies rather than focusing on defending against its effects. Were design teams given the charge in a city of imagining how to create the maximum amount of deaths or destruction with the least amount of money or effort, it would produce a far better roadmap for where we need to focus our attention and to expend limited resources. We need less homeland security, and more homeland creativity applied to the problem of terrorism, seeing it as a competitive strategy good at getting the maximum attention and having the maximum impact for a minimum of means. Viewed in that way, we might employ the wealth of entrepreneurial talent in our midst to begin to develop counter strategies that eliminate the opportunity and nullify the effect of terrorism as we might any competing organization.

Third, designers can help us envision a future other than one in which we forsake our freedoms out of fear. Might the creation a police state and the bankrupting of our public coffers with security measures be just what some terrorists had in mind for us? [6] Instead, we might begin to conceive of a future in which we protect our freedoms as individuals and our liberty as a people with the least surveillance and lowest expenditure possible. What if, rather than the massive offices and ghettoized residential developments in which so many of the wealthy of the world now live and work, we imagine communities of people who know and watch out for each other, who have enough different options of living and working that they can avoid crowds and congestion, and who interact with such a diversity of fellow citizens that no one place will become a target?

We have tended, at least in the U.S., to equate strength and security with a testosterone-laden, toughguy deployment of force, ringing government buildings with barriers and our national borders with walls. That may have been effective when others fought by the same rules as we did. But in the $21^{\text {st }}$ Century, when no amount of military force can counter the actions of a few individuals bent on destroying as much as they can in the process of destroying themselves, we need to change the image we have of strength and security. It will require not just force, but finesse; not just crushing blows, but also creative foils; not just defense intelligence, but design intelligence. The terrorists have shown us how this works. They have proven to be exceptionally inventive in their strategies, from shoe bombs to printer cartridge explosives, and yet equally incompetent in their execution, given the number of failed terrorist attacks we have seen lately. We can do much better than them on both counts, but we first have to stop being terrorized and start thinking creatively.

Maybe the greatest failure of imagination of all in the fight against terrorism, however, lies in our addressing the symptoms rather than the likely underlying causes of the problem. Focusing on the symptoms - the actual terrorist acts themselves leads to an emphasis on security, but were we to focus, instead, on the causes, it would force us to deal with what many in the West do not want to face: the enormous and widening gap between the relatively few wealthy in the world and the vast majority of hopelessly poor. Ending terrorism may ultimately require not arms, but alms.

\section{Conclusion}

To conclude: the best response to terrorism involves not becoming defensive, but going on the offense, understanding how terrorists look for security gaps that they can exploit and anticipating them before they attack. This, in turn, suggests that anti-terrorism needs to involve not just security expertise, but also the imaginativeness and perceptiveness of systems designers to see the world as terrorists do. That also demands that we address the poverty, oppression, and hopelessness that lead people to become terrorists in the first place, which itself remains a major design and policy challenge. 


\section{References}

1. Worldwide Incidents Tracking System: https://wits.nctc.gov/FederalDiscoverWITS/index.d $\mathrm{o} ? \mathrm{~N}=0$

2. Perl, Raphael. Combating Terrorism: The Challenge of Measuring Effectiveness, CRS Report for Congress, March 12, 2007.

3. Ibid.
4. Popper, Karl. The Open Society and its Enemies, Volume 1 and 2. Princeton University Press, Princeton, NJ. 1962.

5. Milanovic, Branko. "True world income distribution, 1988 and 1993: First calculation based on household surveys alone," The Economic Journal, Volume 112 Issue 476. January 2002.

6. Townshend, Charles. Terrorism: A Very Short Introduction. Oxford University Press, Oxford, UK, 2002 